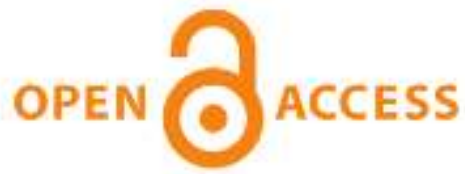

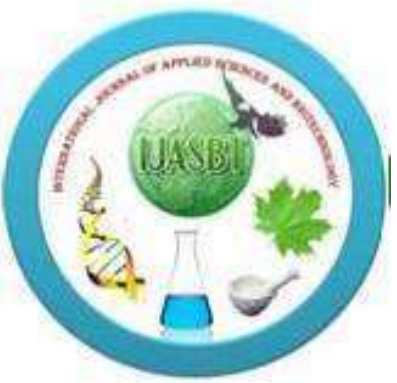 \\ International Journal of Applied Sciences and Biotechnology
}

\author{
A Rapid Publishing Journal
}

ISSN 2091-2609

\section{Indexing and Abstracting}

CrossRef, Google Scholar, Global Impact Factor, Genamics, Index Copernicus, Directory of Open Access Journals, WorldCat, Electronic Journals Library (EZB), Universitätsbibliothek Leipzig, Hamburg University, UTS (University of Technology, Sydney): Library, International Society of Universal Research in Sciences (EyeSource), Journal Seeker, WZB, Socolar, BioRes, Indian Science, Jadoun Science, JourInformatics, Journal Directory, JournalTOCs, Academic Journals Database, Journal Quality Evaluation Report, PDOAJ, Science Central, Journal Impact Factor, NewJour, Open Science Directory, Directory of Research Journals Indexing, Open Access Library, International Impact Factor Services, SciSeek, Cabell's Directories, Scientific Indexing Services, CiteFactor, UniSA Library, InfoBase Index, Infomine, Getinfo, Open Academic Journals Index, HINARI, etc.

\section{CODEN (Chemical Abstract Services, USA): IJASKD}

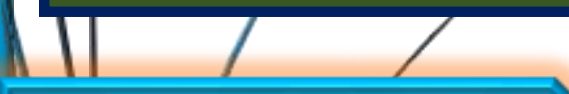

Vol-3(3) September, 2015

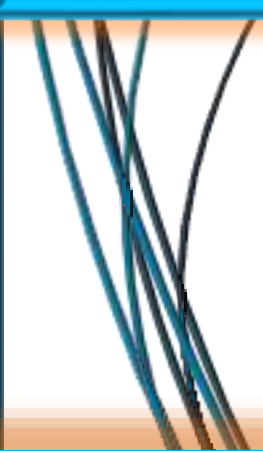

\section{Available online at:}

http://www.ijasbt.org

$\&$

http://www.nepjol.info/index.php/IJASBT/index

Impact factor*: $\mathbf{1 . 4 2 2}$

Scientific Journal Impact factor\#: $\mathbf{3 . 4 1 9}$

Index Copernicus Value: $\mathbf{6 . 0 2}$

SEM-Biotech

Publishing

IBI Factor 2015**: 4.19

*Impact factor is issued by Universal Impact Factor. Kindly note that this is not the IF of Journal Citation Report (JCR). "Impact factor is issued by SJIF INNO SPACE; **Impact factor is issued by INFOBASE INDEX. 


\title{
ENZYMATIC SCREENING AND MOLECULAR CHARACTERIZATION OF THERMOPHILIC BACTERIAL STRAINS ISOLATED FROM HOTSPRING OF TATOPANI, BHURUNG, NEPAL
}

\author{
Hriush Adhikari ${ }^{*}$, Sangam Ghimire ${ }^{1}$, Binod Khatri ${ }^{1}$, Yuvraj K.C ${ }^{2}$ \\ ${ }^{1}$ Department of Biotechnology, SANN International College, Kathmandu, Nepal \\ ${ }^{2}$ Department of Biotechnology, College for Professional Studies, LBEF Campus, Kathmandu, Nepal \\ *Corresponding author’s email: mailforhriush@gmail.com
}

\begin{abstract}
Background and Aim: In Nepal not much of study of Thermophilic area and Thermophiles have been done. Thermophilic bacteria are less studied but are important group of microorganisms due to their ability to produce industrially important enzymes. Methods: In this study, thermophilic bacteria were isolated from hot spring of Bhurung, Nepal. Wide range of bacteria that could grow at high temperatures and tolerate extreme temperature were characterized by morphology, biochemistry and sequencing of its $16 S$ rRNA gene sequence. The isolates were screened for production of extracellular enzymes like protease, amylase, lipase, cellulase, caseinase, pectinase and xylanase activity. Phylogenetic tree construction and $\mathrm{G}+\mathrm{C}$ content evaluation of the isolate was also studied.Results: 15 isolates with ability to tolerate high temperatures were identified as Bacillus sp. by morphology, biochemistry and sequencing of its $16 \mathrm{~S} r R N A$ gene sequence. BLAST search analysis of the sequence was performed and result showed maximum identity (99\% similarity) with Bacillus licheniformis, Bacillus subtilis and Bacillus pumilus. Isolated strains exhibited considerable amount of extracellular exozymes activity. Phylogenetic analysis of the isolates revealed the relatedness among the species. The $\mathrm{G}+\mathrm{C}$ content of each species was also evaluated and was found to be in range of 54.87 to $55.54 \%$. Conclusion: The study of isolates confirmed that the isolated Bacillus sp. to be a true thermophile and could be a source of various thermostable exozymes which can be exploited for pharmaceutical and industrials applications. Much detailed study of the isolates can be done for enhancing the potential of isolates.
\end{abstract}

Key words: Thermophilic Bacteria; Thermostable exozymes; Sequencing; Phylogenetic analysis; G+C content

\section{Introduction}

Microorganisms have been classified according to the temperature at which growth rate is most rapid. Based on this, four major groups i.e. psychrophiles, mesophiles, thermophiles and hyperthermophiles have been described. By definition, thermophiles have their optimal growth temperature between $50^{\circ} \mathrm{C}$ and $80^{\circ} \mathrm{C}$. They can survive in all sorts of inhospitable environments. Studies in the last two decades have revealed that $99 \%$ of bacteria present in the environment are still unexplored or overlooked in laboratory cultivation and hence remain obscure for their ecological functions and unexploited for biotechnological applications (Kellenberger, 2001). Thermophilic bacteria have been less explored due to difficulties in isolation and maintenance of pure culture. Therefore, their diversity and biotechnological potential remains to explored from majority of the thermal habitats. Thermophilic microorganisms have gained worldwide importance due to their tremendous potential to produce thermostable enzymes that have wide applications in pharmaceuticals and industries (Coolbear et al., 1992). Geothermal manifestations occur in more than twenty-eight localities in Nepal, stretching right across a southeast-northwest elongated region. None of the microbial and Biotechnological research have been conducted in the Hot springs locations. Much exploration of thermophilic microrganisms is needed for revealing the potentials of different thermophiles to be used through Biotechnology. Few researches have been conducted by NAST but not much of information is available regarding presence of noble and potential thermophiles in various hotsprings. This is the first detailed microbiological and biotechnological study of Tatopani, Bhurung which aims to characterize thermophilic biodiversity using culture dependent and molecular techniques and screening of enzymes of industrial importance. 


\section{Materials and Methods}

\section{Study site and collection of samples}

Bhurung tatopani is located on Dhaulagiri Zone, Myagdi District, Singa V.D.C. Ward No 4. Tatopani lies on the bank of the Myagdi river west from Beni Bazar, the headquarter of Myagdi District via approximately $9 \mathrm{~km}$ of gravel road. Bhurung Tatopani is one of the hottest amongst 20 hot springs in Nepal and was our chosen site for the isolation of and characterization of thermophilic bacteria. There was a heavy smell of sulphur gas around the sources and the reservoir exhibited a green colour. The estimate terrain elevation above sea level is 2262 metres and is located at Latitude: $28^{\circ} 29^{\prime} 25.3^{\prime \prime} \mathrm{N}$ and Longitude: 83³7'54.06"E. There are 3 different sources of hot springs out of which two springs were selected as study site due to their high temperature. From the Tatopani, combined sediment was collected in a sterile ziplock bag and water samples from two main sources were collected in sterile bottles. In situ measurement of temperature and $\mathrm{pH}$ were taken to create a profile of the hotspring. The temperature of the hot spring during the sampling period was about $60^{\circ} \mathrm{C}$. The $\mathrm{pH}$ was recorded to be in the range of 7.5-9 indicating alkaline environment. The collected samples were kept in Refrigerator at $4^{\circ} \mathrm{C}$ until use.

\section{Isolation of Bacteria}

One gram of soil sample was suspended in $10 \mathrm{ml}$ of sterile distilled water that served as a stock sample for the sediment. $1 \mathrm{ml}$ of this sample and $1 \mathrm{ml}$ each of hot water samples were used for Serial dilutions. The serial dilutions were performed for all four samples and various diluents were inoculated using spread plate and pour plate method in Nutrient agar at $50^{\circ} \mathrm{C}$. After 24-48 hours of incubation, the bacterial colonies were selected based on their morphological characteristics and picked for pure culture on NA medium and were also transferred into freshly prepared nutrient agar slants. The bacterial strains isolated on NA slants were kept at in refrigerator for further study.

\section{Identification and characterization of the isolate}

The selected strains cell morphology and motility were examined by optical microscopy (BX40; Olympus) and growth characteristics were also studied. The isolates were characterized by Gram staining technique. Based on Gram's staining the isolates were found to be Gram-positive and microscopic observation revealed rod shaped which are arranged in chain. Various biochemical tests like endospore formation, motility, IMViC, catalase and oxidase tests were performed. Morphological, microscopic observation and biochemical test indicated the bacteria belonged to be Bacillus sp.

\section{Screening of Enzymes}

Based on the morphology and Microscopy, total 15 thermophilic isolates were assessed for their extracellular enzymatic activity. $1 \mathrm{ml}$ of 12 hour fresh culture was inoculated into $100 \mathrm{ml}$ flask containing Thermus broth and cultured in shaking incubator at $50^{\circ} \mathrm{C}$ at $150 \mathrm{rpm}$. The OD value was noted every 2 hours at $600 \mathrm{~nm}$. After the growth reached Stationary phase the flask was removed. The cell mass was removed and crude the extract was made using centrifuge at $4000 \mathrm{rpm}$ for 15 minutes.

This extract as well as freshly grown cultured of isolates was used for extracellular enzyme screening. Pectinase activity was studied using Pectin Agar medium and Lipase activity of isolates was studied using Tween 80 NA medium. Amylase activity was studied using starch agar plates and observing by incubating the plates and exposing to iodine solution. Protease activity was studied by growing isolates on skimmed milk agar plates. Similarly caseinase activity was also studied by observing the zone of clearance around the colonies or extract after incubation at $50^{\circ} \mathrm{C}$ in Casein $(1 \%)$ nutrient agar plates. Cellulase activity of the isolates was studied on carboxy methyl cellulose (CMC $1 \%$ ) agar. Xylanase activity was studied using Birchwood xylan Agar. Thus 7 different enzyme activities were studied.

\section{PCR amplification and 16S rDNA Sequencing}

Genomic DNA was extracted and purified according to Sambrook and Russell (Sambrook and Russe11, 2001) and its purity was spectrophotometrically assessed by the A260/A280 ratio. The extracted DNA were then amplified. The gene encoding for the $16 S$ rDNA (Edwards et al., 1989) was amplified by PCR using bacterial universal primer pair combination of forward primer $518 \mathrm{~F}$ (5'CCAGCAGCCGCGGTAATACG3') and the reverse primer 800R (5'TACCAGGGTATCTAATCC3'). The reaction volume of $25 \mu \mathrm{l}$ containing $2 \mathrm{ul}$ of $20 \mathrm{ng} / \mathrm{ul}$ template DNA, 1unit of Tag DNA polymerase , $75 \mathrm{mM}$ of $\mathrm{MgCl} 2$, $200 \mu \mathrm{M}$ of DNTPs, $2.5 \mu \mathrm{l}$ of 10X PCR buffer and 5 pmol of each Primer. The Amplification was done in the DNA thermal cycler programmed with $95^{\circ} \mathrm{C}$ for $5 \mathrm{~min}$ followed by 30 cycles of $95^{\circ} \mathrm{C}$ for $1 \mathrm{~min}, 55^{\circ} \mathrm{C}$ for $1 \mathrm{~min}, 72^{\circ} \mathrm{C}$ for 1 min and a final extension of $7 \mathrm{~min}$. Gel electrophoresis was carried out using $1.5 \%$ agarose gel and the amplification was observed under the gel documentation system. The PCR products were purified using the QIAquick PCR purification Kit protocol (Qiagen, Germany) according to manufacturer's instructions and sequenced in Macrogen Inc.Korea. Sequencing reactions were performed in a MJ Research PTC-225 Peltier Thermal Cycler using a ABI PRISM® BigDyeTM Terminator Cycle Sequencing Kits with AmpliTaq ${ }^{\circledR}$ DNA polymerase (FS enzyme) (Applied Biosystems), following the protocols supplied by the manufacturer. Single-pass sequencing was performed on each template using Universial primer. The fluorescentlabeled fragments were purified from the unincorporated terminators with an ethanol precipitation protocol. The samples were resuspended in distilled water and subjected 
to electrophoresis in an ABI 3730xl sequencer (Applied Biosystems).

\section{Homology search and phylogenetic analysis}

The 16S rRNA gene sequences of the selected isolates obtained from Macrogen were compared to the sequences in the public databases using Basic Local Alignment Search Tool (BLAST) in the National Centre for Biotechnology Information (NCBI) website (htt://www.ncbi.nih.gov). Alignment was done using CLASTAL W 2.0. The 16S rDNA gene sequences with high similarity to those determined in the study were retrieved and added to database and aligned with Mega 6 (Tamura et al., 2013). The alignments were corrected manually where necessary by using Sequencher Software 5.3. Phylogenetic trees were constructed by the neighbour-joining method (Saitou and Nei, 1987) with the MEGA6 package (Tamura et al., 2008).

\section{GC study}

Guanine plus cytosine percentage of 15 isolates was calculated and studied using the software ACUA (Umashankar et al., 2007) using the $16 S$ rRNA sequence. The sequences of all bacterial isolates were selected and copied into single notepad format file then uploaded as input files. The GC\% option was selected and the program was run and result was obtained. The result was then saved as excel worksheet and bar diagram was prepared.

\section{Results}

The characteristics of hydrogen sulphide odour was found in water. During samples collection the temperature and $\mathrm{pH}$ of water were measured as shown in Table1.

Total of 15 thermophilic isolates were selected based on microscopy and colony morphology on NA and MA plates. These isolates were also screened for different extracellular enzymatic activities. The strains were assessed for enzymatic activity in terms of zone sizes and substrate digestion at the temperature of $50^{\circ} \mathrm{C}$.
Table 1: Temperature and $\mathrm{pH}$ as noted on May 7th 2010 at 7:00 am

\begin{tabular}{|l|l|l|}
\hline Collection source & Temperature $\left({ }^{\mathbf{}} \mathbf{C}\right)$ & $\mathbf{p H}$ \\
\hline Source 1 & 58 & 7.5 \\
\hline Source 2 & 62 & 8.2 \\
\hline
\end{tabular}

[The environment Temperature was $18^{\circ} \mathrm{C}$. The GPS Position of sampling was 2262 meters Latitude: $28^{\circ} 29^{\prime} 25.3^{\prime \prime} \mathrm{N}$ and Longitude: $83^{\circ} 37^{\prime} 54.06 " \mathrm{E}$ ]

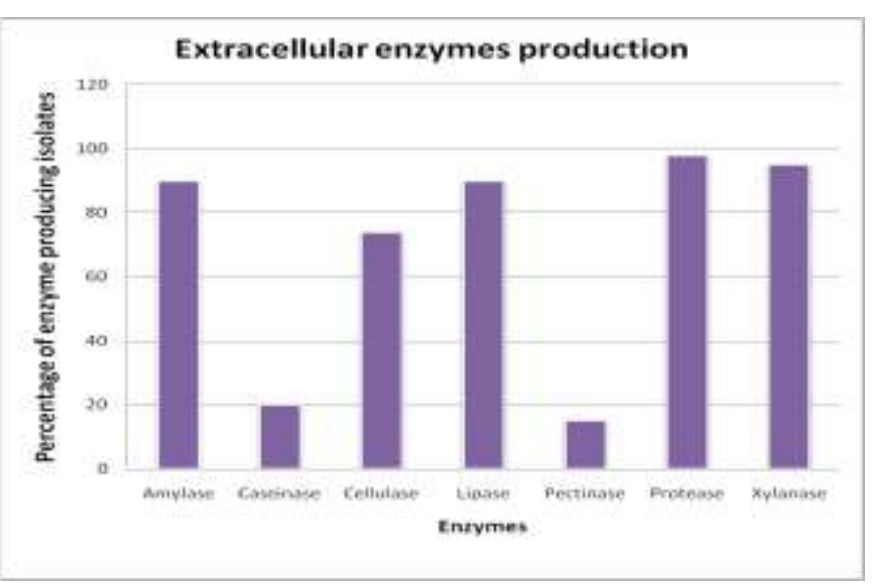

Fig. 1: Extracellular enzyme production profiles of the thermophilic isolates.

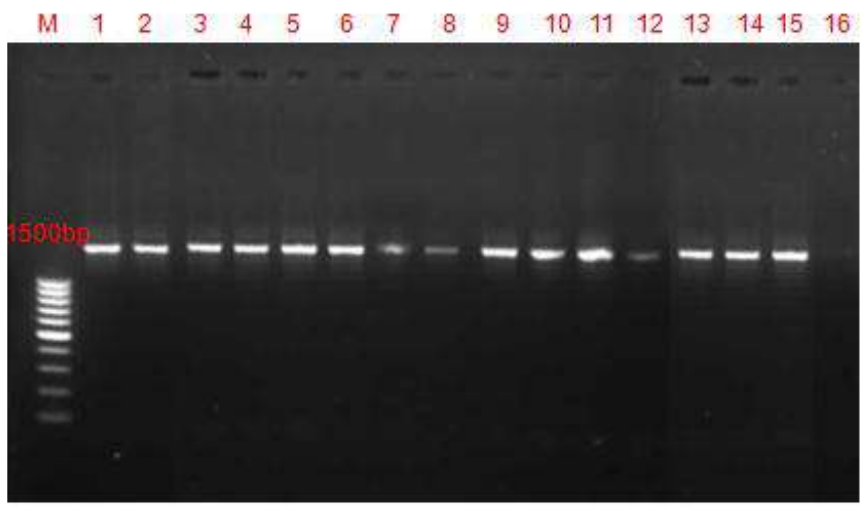

Fig. 2: PCR amplification of 16S rRNA gene region of the Thermophilic isolates

Table 2: Molecular identification of the thermophiles based on $16 S$ rRNA gene sequence.

\begin{tabular}{|l|l|l|}
\hline Isolates & Strain name & Accession number \\
\hline T1 & Bacillus subtilis strain SANN1 & KP975918 \\
\hline T2 & Bacillus subtilis strain SANN2 & KP975919 \\
\hline T3 & Bacillus subtilis strain SANN3 & KP975920 \\
\hline T4 & Bacillus licheniformis strain SANN4 & KP975921 \\
\hline T5 & Bacillus licheniformis strain SANN5 & KP975922 \\
\hline T6 & Bacillus licheniformis strain SANN6 & KP975923 \\
\hline T7 & Bacillus licheniformis strain SANN7 & KP975924 \\
\hline T8 & Bacillus licheniformis strain SANN8 & KP975925 \\
\hline T9 & Bacillus licheniformis strain SANN9 & KP975926 \\
\hline T10 & Bacillus licheniformis strain SANN10 & KP975927 \\
\hline T11 & Bacillus pumilus strain SANN11 & KP975928 \\
\hline T12 & Bacillus pumilus strain SANN12 & KP975929 \\
\hline T13 & Bacillus pumilus strain SANN13 & KP975930 \\
\hline T14 & Bacillus pumilus strain SANN14 & KP975931 \\
\hline T15 & Brevibacillus brevis strain SANN15 & KP975932 \\
\hline
\end{tabular}


The sequence comparison with the Genebank database using BLAST pairwise alignment was done and the strains were given names and accession number that are showed in the following result.

The sequence information was also used for the construction of Phylogeny using the Molecular
Evolutionary Genetic Analysis software (MEGA) version 6.0 .

Neighbour-joining tree based on $16 S$ rRNA gene sequences, showing the phylogenetic relationships between the isolates. Bootstrap values as percentages of 1000 replicates are given at branch points; only values $>50 \%$ are shown.

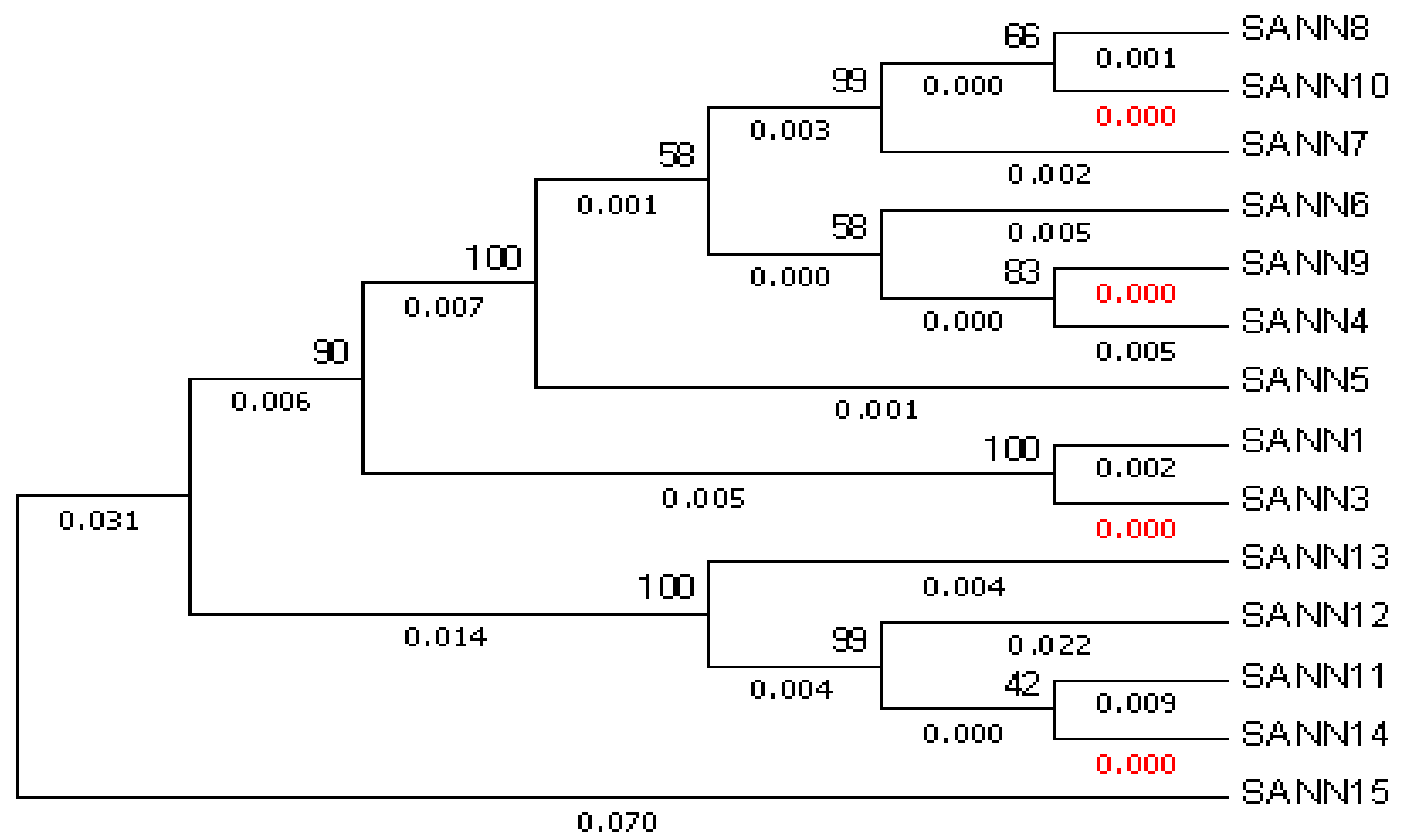

Fig 3: Phylogeny of the thermophilic isolates based on $16 \mathrm{~S} r R N A$ gene sequence information using MEGA-6.0

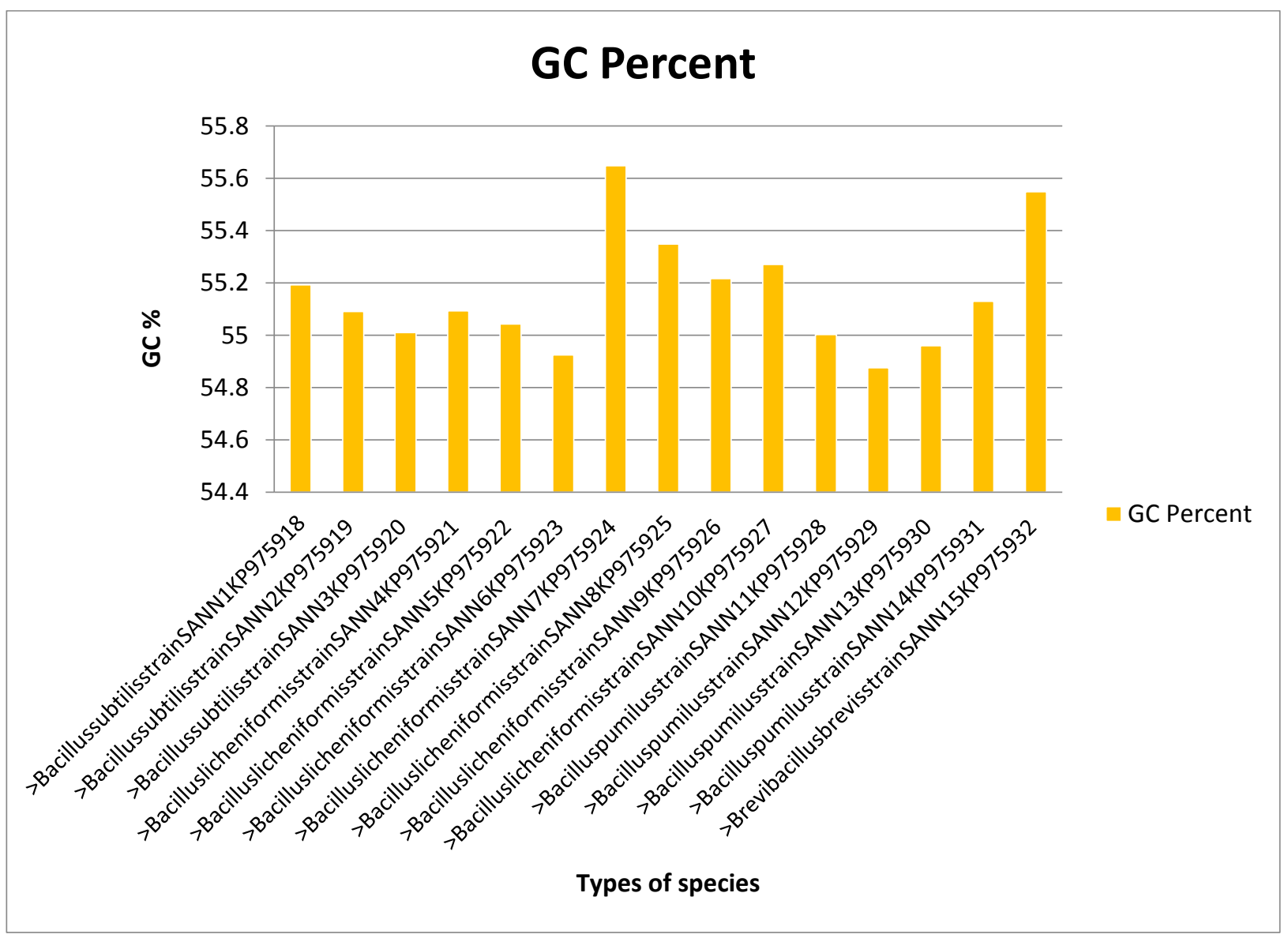

Fig. 4: GC percentage of the Bacillus isolates 


\section{Discussion}

Microbial enzyme occupies a prominent position in modern biotechnology (Cowan, 1996). The majority of the industrial enzymes known to date have been derived from bacteria and fungi (Haki and Rakshit, 2003). Therefore isolation of the microbe of hot springs and its identification is an important task for modern scientist. We recorded very significant Amylase and Protease activity including others in the isolated strains. The sequence comparison showed that the query sequence coverage was almost $100 \%$ and identity was above $99 \%$ with the database sequence. Out of the total isolates, one isolate was found to sustain temperatures up to $90^{\circ} \mathrm{C}$. The ability of the bacterium to tolerate this temperature indicated to be thermophile. Narayan have also characterized bacterial isolates as thermophiles from Savusavu hotspring in Fiji by determining their growth at $90^{\circ} \mathrm{C}$ (Narayan et al., 2008). The bacterium was identified as Bacillus sp. both by morphological and molecular characterization. Similar work carried out by Rath C (Rath, 1999) has also reported thermophilic Bacillus and Pseudomonas species from three hot springs of Odisha, India. Thermophilic and hyperthermophilic microorganisms have the ability to produce wide variety of thermostable enzymes. Rath C (Rath et al., 2010) have also reported various extracellular enzymes from some thermophilic bacteria isolated from the same hot spring. However, those bacteria were not characterized. Several workers have reported protease activity from thermophilic Bacillus species (Guangrong et al., 2006; Vi jayalakshmi et al., 2011). Proteases are essential constituents of all forms of life on earth including prokaryotes, fungi, plants and animals. Proteases are highly exploited enzymes in food, leather, detergent, pharmaceutical, diagnostics, waste management and silver recovery (Babu and Lakshmi, 2005). Bacillus protease is of special importance because of its wide applications in various industries like pharmaceutical, leather, food and waste processing industries (Pastor et al., 2001). The GC content of the isolate was also found to be relatively high. This might be the reason for its ability to survive in high temperature. However, recent report of $\mathrm{Wu}$ (Wu et al., 2012) suggests that higher GC content could not only be the sole reason for an organism to survive in extreme temperature. There were of the opinion that organisms isolated from soil preferably have higher GC content than aquatic isolates. Similarly, Hurst and Merchant (Hurst et al., 2001) reported that high GC content is not an adaptation to high temperature among prokaryotes. The phylogenetic tree constructed showed the isolates are closely related with each other.

\section{Conclusion}

Our study revealed different thermostable extracellular enzymatic activity of bacterial strains isolated from a local hot springs of Bhurung. The sequence information obtained was good enough for the molecular identification. Further optimization of growth parameters for optimum extracellular enzymatic activity of the isolated bacterial strains can be performed. The gene can be identified and cloned to produce recombinant enzymes and further used for industrial production.

\section{Acknowledgements}

We are highly grateful to Prof. Dr. Mukunda Ranjit, Dr Subash Ghimire, Er. Dilip Bhattarai and all the staffs of Department of Biotechnology, SANN International College, Gairidhara, Kathmandu, Nepal for providing all the support during study period.

\section{References}

Babu NKS and Lakshmi KD (2005) Optimization of thermostable alkaline protease production from species of Bacillus using rice bran. African Journal of Biotechnology. 4: 724726. DOI: 10.5897/AJB2005.000-3132

Coolbear T, Daniel R, Morgan HW (1992) The enzymes from extreme thermophiles, bacterial sources, thermostability and industrial relevance. Adv Biochem Eng Biotechnol. 45: 57-98. DOI: $10.1007 / \mathrm{bfb} 0008756$

Daniel, R. M., Dines, M., and Petach, H. H (1996) The denaturation and degradation of stable enzymes at high temperatures. Biochemical Journal, 317 (Pt 1): 1-11. DOI: 10.1042/bj3170001

Edwards U, Rogall T, Blöcker H, Emde M and Böttger EC (1989) Isolation and direct complete nucleotide determination of entire genes. Characterization of a gene coding for $16 \mathrm{~S}$ ribosomal RNA. Nucleic Acids Research. 17(19): 78437853. DOI: $10.1093 /$ nar/17.19.7843

Guangrong H, Tiejing Y, Po H and Jiaxing J (2006) Purification and characterization of a protease from Thermophilic Bacillus strain HS08. African Journal of Biotechnology. 5: 2433-2438.

Haki GD and Rakshit SK (2003) Developments in industrially important thermostable enzymes: a review. Biores Technol. 89: 17-34. DOI: 10.1016/S09608524(03)00033-6

Hurst LD and Merchant AR (2001) High guanine-cytosine content is not an adaptation to high temperature: a comparative analysis amongst prokaryotes. Proceedings of the Royal Society B: Biological Sciences, 268(1466): 493-497. DOI: $10.1098 / \mathrm{rspb} .2000 .1397$

Kellenberger E (2001) Exploring the unknown: The silent revolution of microbiology. EMBO Reports, 2(1), 5-7. DOI: 10.1093/embo-reports/kve014

Narayan VV, Hatha MA, Morgan HW and Rao D (2008) Isolation and characterization of aerobic thermophilic bacteria from Savusavu hot springs in Fiji. Microbes Environ. 23: 350352. DOI: 10.1264/jsme2.ME08105

Panda MK, Sahu MK and Tayung K (2013) Isolation and characterization of a thermophilic Bacillus sp. with protease activity isolated from hot spring of Tarabalo, 
Odisha, India. Iranian Journal of Microbiology. 5(2), 159-165.

Pastor MD, Lorda GS, Balatti (2001) A Protease obtention using Bacillus subtilis 3411 and amaranth seed meal medium at different aeration rates. Brazilian Journal of Microbiology. 32: $\quad 1-8$. DOI: $10.1590 / \mathrm{S} 1517-$ 83822001000100002

Rao MB, Tanksale AM, Ghatge MS and Deshpande VV (1998) Molecular and Biotechnological Aspects of Microbial Proteases. Microbiology and Molecular Biology Reviews. 62(3): 597-635.

Rath CC (1996) Heat stable lipase activity of thermo-tolerant bacteria from hot springs at Orissa, India. Industrial enzyme technology. Trends Biotechnology.14: 177-178.

Saitou N and Nei M (1987) The neighbor-joining method: A new method for reconstructing phylogenetic trees. Molecular Biology and Evolution. 4:406-425.
Sambrook J and Russell D (2001) Molecular Cloning A laboratory manual. Cold Spring Harbor. NewYork.

Tamura K, Stecher G, Peterson D, Filipski A and Kumar S (2013) MEGA6: Molecular Evolutionary Genetics Analysis Version 6.0. Molecular Biology and Evolution .30: 27252729. DOI: $10.1093 / \mathrm{molbev} / \mathrm{mst} 197$

Vetrivel U, Arunkumar V and Dorairaj S (2007) ACUA: A software tool for automated codon usage analysis. Bioinformation, 2(2): 62-63. DOI: $10.6026 / 97320630002062$

Vijayalakshmi S, Venkatkumar S and Thankamani V (2011) Screening of alkalophilic thermophilic protease isolated from Bacillus RV.B2.90 for industrial applications. Res Biotechnology.2: 32-41.

Wu H, Zhang Z, Hu H, and Yu J (2012) On the molecular mechanism of GC content variation among eubacterial genomes. Biology Direct.7: 2. DOI: 10.1186/1745-6150$7-2$ 